\title{
A Survey of Cerebrospinal Fluid Total Protein Upper Limits in Canada: Time for an Update?
}

\author{
Pierre R. Bourque, Christopher R. McCudden, Jodi Warman-Chardon, \\ John Brooks, Harald Hegen, Florian Deisenhammer, Ari Breiner
}

\begin{abstract}
Background: The antiquated standard reference range of $0.15-0.45 \mathrm{~g} / \mathrm{L}$ for cerebrospinal fluid total protein (CSF-TP) is well entrenched in medical literature and laboratory operating procedures across the world. Methods: We conducted a web-based survey with a response rate of $34.9 \%$ through the listserv of the Canadian Neurological Sciences Federation. Additional laboratory reference data were collated by telephone interview of hospital laboratory technologists across Canada. Results: A total of 142 site responses were obtained: $64.1 \%$ from academic/tertiary hospitals and $35.9 \%$ from community hospitals. A strong majority (80.4\%) of both types of institutions reported using a CSF-TP upper reference limit of $0.45 \mathrm{~g} / \mathrm{L}$ or less. As a rule, no age adjustments were implemented in CSF-TP-level interpretation. Conclusions: Recent well-powered laboratory reference studies have documented CSF-TP upper reference limits that are above $0.6 \mathrm{~g} / \mathrm{L}$ starting at age 50, with incremental limits partitioned by subsequent decades of age. The conventional $0.45 \mathrm{~g} / \mathrm{L}$ limit could lead to false positive results. Our survey suggests there is a need to consider a wide adoption of data-driven, rather than historical, reference values.
\end{abstract}

RÉSUMÉ: N'est-il pas temps de procéder à une mise à jour en ce qui regarde les limites de référence supérieures du taux de protéines du liquide céphalo-rachidien utilisées au Canada ? Contexte: Maintenant désuète, la plage normale de référence de 0,15 à $0,45 \mathrm{~g} / \mathrm{L}$ en ce qui regarde le taux de protéines du liquide céphalo-rachidien (LCR) continue à être bien ancrée dans la littérature médicale et les procédures opérationnelles des laboratoires, et ce, partout dans le monde. Méthodes: À ce sujet, nous avons effectué un sondage en ligne ayant obtenu un taux de réponse de 34,9\%. Pour ce faire, nous avons fait appel à la liste de diffusion de la Fédération des sciences neurologiques du Canada. Nous avons également collecté des données additionnelles au moyen d'entrevues téléphoniques conduites avec des technologues de laboratoire travaillant en milieu hospitalier à l'échelle du Canada. Résultats: Au total, 142 établissements de santé ont fourni des réponses : 64,1 \% étaient des hôpitaux universitaires et tertiaires tandis que 35,9\% étaient des établissements de type communautaire. Une grande majorité d'établissements des deux types $(80,4 \%)$ ont signalé, en ce qui regarde le taux de protéines du LCR, se baser sur une limite de référence supérieure de $0,45 \mathrm{~g} / \mathrm{L}$ ou moins. En règle générale, aucun ajustement en fonction de l'âge n'était mis en œuvre au moment d'interpréter le taux total de protéines du LCR. Conclusions: Des études de cas récentes menées en laboratoire et reposant sur des preuves solides ont établi des limites de référence supérieures dépassant $0,6 \mathrm{~g} / \mathrm{L}$ à partir de $50 \mathrm{ans}$, les augmentations des limites étant par la suite déterminées en fonction de périodes subséquentes de 10 ans d'âge. Il s'ensuit donc que la limite conventionnelle de $0,45 \mathrm{~g} / \mathrm{L}$ pourrait entraîner des faux négatifs. Notre sondage suggère ainsi dans une grande mesure qu'il est nécessaire d'adopter des limites de référence reposant sur des données probantes plutôt que sur des limites de référence de nature historique.

Keywords: General neurology, Immunology, Inflammatory diseases, Neuroimmunology, Cerebrospinal fluid

doi:10.1017/cjn.2019.12

Can J Neurol Sci. 2019; 46: 283-286

\section{BACKGROUND}

Cerebrospinal fluid (CSF) analysis remains an important tool in the assessment of infectious or autoimmune disorders of both the central and peripheral nervous systems. For CSF Total Protein (CSF-TP) obtained by lumbar puncture, a reference range of $0.15-0.45 \mathrm{~g} / \mathrm{L}$ (or $15-45 \mathrm{mg} / \mathrm{dL}$ ) is very frequently quoted in medical literature and has been widely implemented in hospital clinical laboratories. This specific range of values can be traced back to a monograph published by H. Houston Merritt in $1938 .^{1}$
Despite its broad use across Canada and the world, concerns can be raised about this reference range: (1) values may be derived from small sample sizes studying young healthy volunteers, using outdated laboratory techniques; (2) only the upper limit typically is usually considered diagnostically relevant; and (3) the reference values are not incrementally adjusted in later decades of life. More recent reference studies done in a rigorous fashion, suggest that age-dependent and significantly higher upper limits (above $0.6 \mathrm{~g} / \mathrm{L}$ after the age 50 years) are more representative. ${ }^{2,3}$

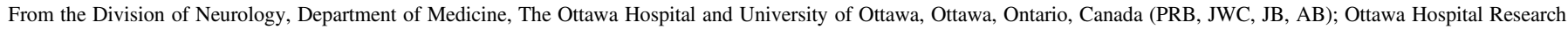

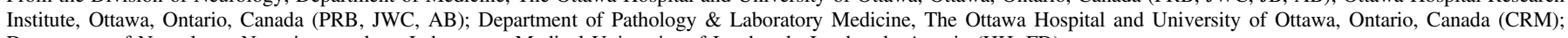
Department of Neurology, Neuroimmunology Laboratory, Medical University of Innsbruck, Innsbruck, Austria (HH, FD)

Received November 28, 2018. Final Revisions Submitted January 12, 2019. Date of Acceptance January 24, 2019.

Correspondence to: Pierre R. Bourque, The Ottawa Hospital, 1053 Carling Ave., Ottawa, Ontario K1Y 4E9, Canada. Email: pbourque@toh.ca 


\section{Table 1: Web-based questionnaire and response options}

\begin{tabular}{l} 
1. What is the upper limit of normal for CSF-TP at your institution? \\
\hline a. $0.45 \mathrm{~g} / \mathrm{L}(45 \mathrm{mg} / \mathrm{dL})$ or less \\
\hline b. $0.60 \mathrm{~g} / \mathrm{L}(60 \mathrm{mg} / \mathrm{dL})$ or less \\
\hline c. Other values, specify: \\
\hline 2. For adult subjects, do you use different upper limits with advancing age \\
(e.g. $<50$ years, $>50$ years) \\
\hline a. Yes \\
\hline b. No \\
\hline 3. What is the source of your institution's reference limits? \\
\hline a. Standard Lab Medicine reference values \\
\hline b. Institution-specific reference values, derived from local data \\
\hline c. I don't know
\end{tabular}

We have recently reported results of a web-based survey to assess what CSF-TP upper reference values are used in clinical hospital laboratory hospitals worldwide. ${ }^{4}$ In the present paper, we offer an in-depth examination of data from Canadian hospital centers, with the goal of understanding current practice patterns in academic and community institutions and determining if there is a need to update reference limits in Canada.

\section{Methods}

The Ottawa Hospital Research Institute Ethics Board approved the electronic distribution of a survey on institutional CSF-TP reference ranges (protocol \#20170816-01H). This survey was distributed worldwide and was comprised of three simple questions (Table 1). ${ }^{4}$ For Canadian centers, permission was granted by the Canadian Neurological Sciences Federation (CNSF) for distribution to Full/Active members. In the event of duplicate responses for the same institution, the highest value was chosen if answers differed.

Additional responses to the survey question \#1 were obtained by telephoning biochemistry technologists in individual clinical hospital laboratories across the country. We limited this question to sites where CSF protein is measured locally (as opposed to external/reference laboratory sample analysis). The contact numbers for these laboratories were obtained by consulting hospital directories of Canadian provincial and territorial health services websites. Every effort was made to include smaller community health centers and offer a wide geographical representation.

Web-based and telephone interview results were collated in a spreadsheet documenting geographical location, universityaffiliated tertiary vs community hospital, CSF-TP upper limit in $\mathrm{g} / \mathrm{L}$, and whether an age-dependent adjustment was reported. Mean CSF-TP upper limit values were compared between tertiary and community hospitals using a T-test for independent samples.

\section{ReSUlts}

The web-based survey was distributed to 275 email addresses through the CNSF and yielded 96 responses, for a response rate of $34.9 \%$. The survey completion rate was $100 \%$. After the removal of duplicate hospital answers, there were 51 unique responses, with

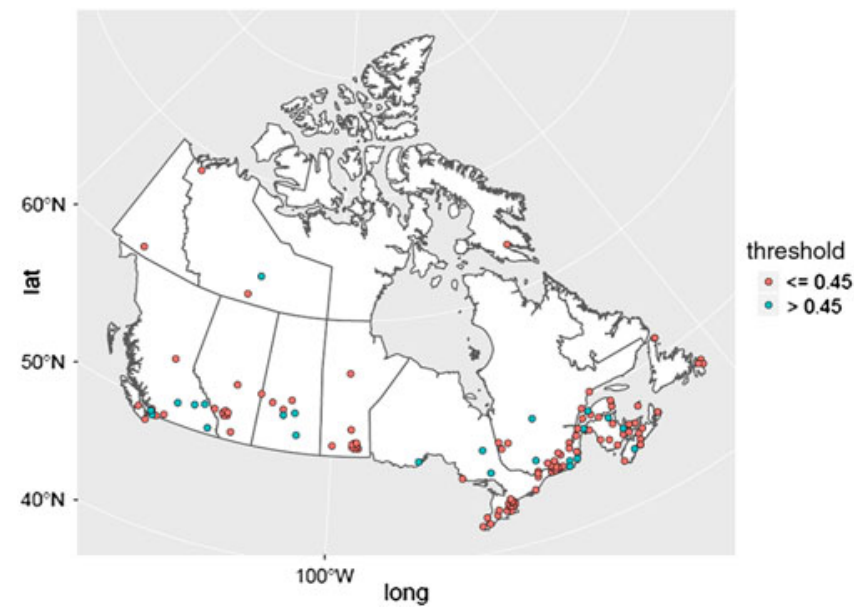

Figure 1: Canadian geolocation map for 142 hospital laboratories $C S F-T P$ reference values. Hospital centers are represented in red if the CSF-TP upper limit is $\leq 0.45 \mathrm{~g} / \mathrm{L}$ and in blue if the CSF-TP upper limit is $>0.45 \mathrm{~g} / \mathrm{L}$. The geographical distribution is as follows: North West Territories (3), Yukon (1), Nunavut (1), British Columbia (13), Alberta (11), Saskatchewan (8), Manitoba (13), Ontario (28), Quebec (39), New Brunswick (9), Nova Scotia (10), Prince-Edward Island (2), and Newfoundland (4).

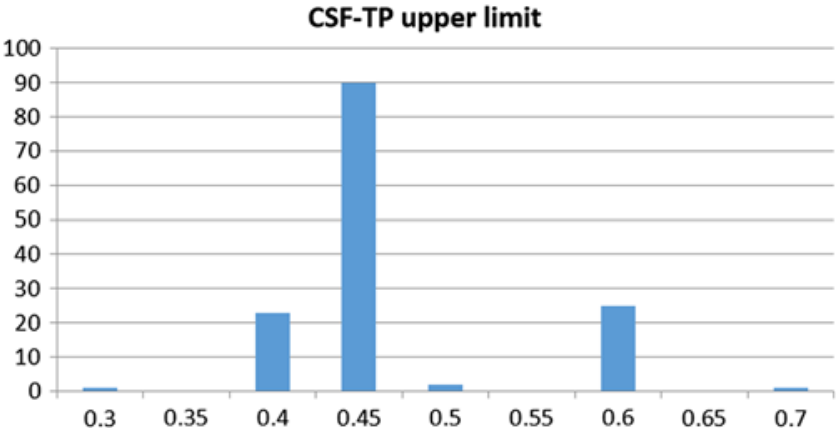

Figure 2: Frequency distribution of CSF-TP upper limit values (g/L, x-axis) in 142 Canadian hospital centers (y-axis).

a predominance of tertiary academic hospitals with university affiliation $(72.5 \%)$. All (100\%) the responders indicated they did not use age-dependent CSF-TP reference ranges beyond the neonatal period. When asked about the origin of their institutional reference values, $78.8 \%$ chose "unknown" and $21.2 \%$ chose "institutional/local data." An additional 91 telephone responses limited to CSF-TP upper limit were obtained from laboratory personnel. Only a single laboratory reported that a higher reference limit was applied to adults over the age of 60 years. The telephone contact list excluded university hospitals already covered in the CNSF web-based survey, resulting in a much higher proportion of community hospitals (84\%).

Figure 1 provides a geolocation map for the total data set of 142 Canadian hospital laboratory unique responses, demonstrating country-wide representation. This included responses from 91 $(64.1 \%)$ community hospitals and $51(35.9 \%)$ academic/tertiary care institutions. The frequency distribution of CSF-TP upper limits is displayed in Figure 2. A value of $0.45 \mathrm{~g} / \mathrm{L}$ or less was reported by 114 centers $(80.4 \%)$. A value of $0.6 \mathrm{~g} / \mathrm{L}$ or more was reported by 26 centers $(18.2 \%)$. The mean CSF-TP upper limit 
was $0.468 \mathrm{~g} / \mathrm{L} \pm 0.060$ for university-affiliated centers and $0.473 \mathrm{~g} / \mathrm{L} \pm 0.074$ for community hospitals. Comparison of this data using a two-tailed T-test for independent samples did not show a statistically significant difference $(p=0.716)$.

\section{Discussion}

Our survey reveals that over $80 \%$ of 142 Canadian hospital laboratories report a CSF-TP upper reference range of $0.45 \mathrm{~g} / \mathrm{L}$ or less, with no significant difference between academic or community hospitals. Similar findings were noted in a survey of 84 hospital laboratories in the UK where only $7 \%$ of centers used a value greater than $0.45 \mathrm{~g} / \mathrm{L}$ and none reported age-adjusted reference ranges for adults. ${ }^{5}$ In the majority of cases $(78.8 \%)$, physician and hospital laboratory personnel were not aware of how this reference limit was derived.

The commonly stated upper reference limit of $0.45 \mathrm{~g} / \mathrm{L}$ can be traced back to literature from the $1930 \mathrm{~s}^{1}$ and has been subsequently widely reiterated in medical literature as well as in lab reference manuals. Lumbar punctures are invasive procedures, usually performed when there is a significant suspicion of a disorder of the central or peripheral nervous systems. Hospital laboratories would not be expected to routinely conduct institution-specific reference studies, but would typically rely on published literature.

Few studies have assessed neurologically normal volunteers, and such studies were comprised of small cohorts of young adults. ${ }^{6-9}$ This limits the accuracy of the reference range and does not account for the rise in CSF-TP with increasing age. The best alternative strategy to define a reference sample may consist in analyzing CSF samples in a hospital laboratory database. The process of identifying suitable reference samples can start with CSF laboratory criteria, such as the exclusion of samples with abnormal white blood cell count, red blood cell count, or glucose level. It is imperative to conduct an additional clinical chart and broader laboratory review to exclude conditions known to be associated with CSF protein elevation, such as known spinal disorders, meningeal infection, tumors, multiple sclerosis, inflammatory or diabetic neuropathy, etc. The reference population thus selected is likely to consist of patients who eventually were found to have a neurologically benign final diagnosis such as non-aneurysmal headache, psychiatric disease, transient metabolic encephalopathy, or negative screening for malignancy. Obviously, this type of reference study might be confounded by an asymptomatic spinal spondylarthrosis, causing an elevation of CSF protein at the level of the lumbar cistern through a mechanism of sequestration. ${ }^{10,11}$ Published reference studies have not required spinal imaging to systematically exclude this possibility, but it can be considered that it would similarly confound the assessment of CSF-TP in healthy volunteers. Two recent studies, published by groups in Austria $^{3}$ and Canada $^{2}$ using modern laboratory equipment and very consistent selection criteria, reached remarkably similar results, stratified by age. Based on these studies, one can extrapolate a more rigorous CSF-TP upper reference limit of $0.5 \mathrm{~g} / \mathrm{L}$ for age $<30$ years, $0.55 \mathrm{~g} / \mathrm{L}$ for age $30-49,0.6 \mathrm{~g} / \mathrm{L}$ for ages $50-59$, and values reaching above $0.65 \mathrm{~g} / \mathrm{L}$ beyond the age of 60 years.

A false positive determination of raised CSF-TP, based on an incorrect reference range, may lead to an erroneous diagnosis of albuminocytologic dissociation and the unwarranted suspicion of abnormal permeability of the blood-brain or blood-nerve barriers.
It may trigger unnecessary neuroimaging, nerve conduction studies, repeat lumbar puncture, or additional investigations for inflammatory disorders of the central or peripheral nervous systems. A striking example is the risk of misdiagnosis of chronic inflammatory demyelinating polyradiculoneuropathy (CIDP), as was documented in a case series from a tertiary care referral center. ${ }^{12}$ In this case series, an important source of error was undue reliance on "mild to moderate" CSF-TP elevation, possibly confounded by incorrect reference limits. The erroneous diagnosis of CIDP often leads to unnecessary treatment with immunomodulatory therapies including intravenous immunoglobulin.

Our study is subjected to the common limitations of web-based surveys. The response rate of $34.9 \%$ is in line with what can be expected for medical specialists in general, though one Canadian study documented a higher response rate for neurologists and neurosurgeons. ${ }^{13}$ The web-survey distribution list obtained through the CNSF favored responses from academic hospitals. This bias had to be corrected by a complementary data collection strategy (direct phone contact), to allow for a wider representation of community hospital laboratories.

Apart from refining the CSF-TP reference range, it is also worthwhile to note that many academic research centers are moving toward analysis of other indices to determine the integrity of the blood-brain barrier, the increased intrathecal production, or the abnormal release or sequestration of specific brain proteins. Examples of these other indices include the CSF/serum albumin ratio $\left(Q_{\text {alb }}\right),{ }^{14}$ the detection of CSF oligoclonal bands, ${ }^{15}$ serum neuron-specific enolase, ${ }^{16}$ serum S-100,${ }^{17}$ and CSF tau, ${ }^{18}$ amyloid precursor protein, ${ }^{19}$ or synuclein. ${ }^{20}$ However, for the time being, many of these are specialty tests which are not widely available and subject to the same challenge of defining reference populations. The readily accessible measure of CSF-TP remains by far the most widely used CSF protein measurement in Canada and in the world. Although it has well-acknowledged limitations in diagnostic sensitivity and specificity, its interpretation still warrants evidence-based reference limits. The survey we presented here reveals a significant gap in knowledge translation - despite strong evidence from recent publications, there has not yet been a shift in institutional standard operational procedures. The Canadian experience is likely reflective of a similar worldwide discrepancy, suggesting a need to widely apply data-driven, rather than historical, reference limits.

\section{ACKNOWLEDGEMENTS}

The authors extend thanks to Ms. Donna Irvin and the leadership of the CNSF for allowing a successful distribution of the survey, and to Ms. J. Klaas for her help with collating responses from clinical laboratories.

\section{Disclosures}

The authors have no conflicts of interest to declare.

\section{STATEMENTS OF AUTHORSHIP}

PR: Survey distribution and data entry, and manuscript draft and revisions.

CRM: Critical review of manuscript, with emphasis on laboratory reference criteria. 
JWC: Critical review of manuscript.

JB: Critical review of manuscript

$\mathrm{HH}$ : Critical review of manuscript, with emphasis on laboratory reference interpretation.

FD: Critical review of manuscript.

$\mathrm{AB}$ : Interpretation of data, literature review, and manuscript revision

\section{REFERENCES}

1. Merritt HH, Fremont-Smith F. The cerebrospinal fluid. Philadelphia: W.B. Saunders; 1938.

2. McCudden CR, Brooks J, Figurado P, Bourque PR. Cerebrospinal fluid total protein reference intervals derived from 20 years of patient data. Clin Chem. 2017;63(12):1856-65.

3. Hegen H, Auer M, Zeileis A, Deisenhammer F. Upper reference limits for cerebrospinal fluid total protein and albumin quotient based on a large cohort of control patients: implications for increased clinical specificity. Clin Chem Lab Med. 2016;54(2): 285-92.

4. Bourque PR, Breiner A, Moher D, et al. Adult CSF total protein: higher upper reference limits should be considered worlwide. A web-based survey. J Neurol Sci. 2019;396:48-51.

5. Holbrook I, Beetham R, Cruickshank A, et al. National audit of cerebrospinal fluid testing. Ann Clin Biochem. 2007;44(Pt 5): 443-8.

6. Ben Menachem E, Persson L, Schechter PJ, Haegele KD, Huebert N, Hardenberg J. Cerebrospinal fluid parameters in healthy volunteers during serial lumbar punctures. J Neurochem. 1989;52(2): 632-5.

7. Stibler $\mathrm{H}$. The normal cerebrospinal fluid proteins identified by means of thin-layer isoelectric focusing and crossed immunoelectrofocusing. J Neurol Sci. 1978;36(2):273-88.

8. Gilland O. Lumbar cerebrospinal fluid total protein in healthy subjects. Acta Neurol Scand. 1967;43(4):526-9.

9. Merril CR, Harrington MG. "Ultrasensitive" silver stains: their use exemplified in the study of normal human cerebrospinal fluid proteins separated by two-dimensional electrophoresis. Clin Chem. 1984;30(12):1938-42.

10. Ahonen A, Myllyla VV, Hokkanen E. Cerebrospinal fluid protein findings in various lower back pain syndromes. Acta Neurol Scand. 1979;60(2):93-9.

11. Skouen JS, Larsen JL, Gjerde IO, Hegrestad SE, Vollset SE. Cerebrospinal fluid protein concentrations in patients with sciatica caused by lumbar disc herniation: an investigation of biochemical, neurologic, and radiologic predictors of long-term outcome. J Spinal Disord. 1997;10(6):505-11.

12. Allen JA, Lewis RA. CIDP diagnostic pitfalls and perception of treatment benefit. Neurology. 2015;85(6):498-504.

13. Cunningham CT, Quan H, Hemmelgarn B, et al. Exploring physician specialist response rates to web-based surveys. BMC Med Res Methodol. 2015;15:32.

14. Deisenhammer F, Bartos A, Egg R, et al. Guidelines on routine cerebrospinal fluid analysis. Report from an EFNS task force. Eur J Neurol. 2006;13(9):913-22.

15. Freedman MS, Thompson EJ, Deisenhammer F, et al. Recommended standard of cerebrospinal fluid analysis in the diagnosis of multiple sclerosis: a consensus statement. Arch Neurol. 2005;62(6):865-70.

16. Zandbergen EG, Hijdra A, Koelman JH, et al. Prediction of poor outcome within the first 3 days of postanoxic coma. Neurology. 2006;66(1):62-8.

17. Branco JP, Oliveira S, Sargento-Freitas J, et al. S100beta protein as a predictor of poststroke functional outcome: a prospective study. J Stroke Cerebrovasc Dis. 2018;27(7):1890-6.

18. Shaw LM, Arias J, Blennow K, et al. Appropriate use criteria for lumbar puncture and cerebrospinal fluid testing in the diagnosis of Alzheimer's disease. Alzheimer's Dement. 2018;14(11): 1505-21.

19. Constantinides VC, Paraskevas GP, Emmanouilidou E, et al. CSF biomarkers beta-amyloid, tau proteins and a-synuclein in the differential diagnosis of Parkinson-plus syndromes. J Neurol Sci. 2017;382:91-5.

20. Shi M, Tang L, Toledo JB, et al. Cerebrospinal fluid alpha-synuclein contributes to the differential diagnosis of Alzheimer's disease. Alzheimer's Dement. 2018;14(8):1052-62. 